\title{
Adherence to lipid-lowering treatment: the patient perspective
}

\author{
This article was published in the following Dove Press journal: \\ Patient Preference and Adherence \\ 7 November 2012 \\ Number of times this article has been viewed
}

\author{
Manuela Casula' \\ Elena Tragni' \\ Alberico Luigi Catapano ${ }^{1,2}$ \\ 'Epidemiology and Preventive \\ Pharmacology Centre (SEFAP), \\ Department of Pharmacological \\ Sciences, University of Milan, Milan, \\ Italy; ${ }^{2} I R C C S$ MultiMedica, Sesto San \\ Giovanni, Italy
}

\begin{abstract}
Despite the widespread prescription of highly effective lipid-lowering medications, such as the HMG-CoA reductase inhibitors (statins), a large portion of the population has lipid levels higher than the recommended goals. Treatment failures have been attributed to a variety of causes but the most important is likely to be poor adherence to therapy in the form of irregular or interrupted intake and the high frequency of discontinuation or lack of persistence. Adherence is a multidimensional phenomenon determined by the interplay of patient factors, physician factors, and health care system factors. Patients' knowledge and beliefs about their illness, motivation to manage it, confidence in their ability to engage in illness-management behaviors, and expectations regarding the outcome of treatment and the consequences of poor adherence interact to influence adherence behavior. Patient-related factors account for the largest incremental explanatory power in predicting adherence. This article provides an overview of this critical issue, focusing on patient role in determining adherence level to lipid-lowering therapy.
\end{abstract}

Keywords: hyperlipidemia/drug therapy, medication adherence, patient preference, health behavior

Raised cholesterol levels increase the risk of heart disease and stroke. Globally, a third of ischemic heart disease is attributable to high cholesterol. Overall, raised cholesterol is estimated to cause 2.6 million deaths (4.5\% of total). ${ }^{1}$ Despite the widespread prescription of highly effective lipid-lowering medications, such as the HMG-CoA reductase inhibitors (statins), a large portion of the population has lowdensity lipoprotein cholesterol (LDL-C) levels greater than the recommended goals. In America, on the basis of recent National Health and Nutrition Examination Survey (NHANES) data, it has been estimated that 71 million US adults have LDL-C greater than the National Cholesterol Education Program Adult Treatment Panel III (NCEP ATP-III) goals, but only 34 million (48.1\%) received lipid-lowering treatment (including nondrug therapy) and 23 million (33.2\%) achieved the NCEP ATP III LDL-C goal. ${ }^{2}$ According to EUROASPIRE III survey data, in Europe, the proportion of patients whose lipid levels are not at target is $46.2 \%{ }^{3}$

Failures in LDL-C goal achievement have been attributed to a variety of causes, including an improper titration of the starting statin dose $\mathrm{e}^{4,5}$ and lack of follow up, but perhaps the most important is poor adherence to treatment, in the form of irregular or interrupted intake and high frequency of discontinuation or lack of persistence. ${ }^{6,7}$ It has been reported that $50 \%$ or more of patients discontinue statin medication within 1 year after treatment initiation and that consistency of use decreases over time. ${ }^{8}$ 
The management of a symptomless condition such as dyslipidemia poses a serious challenge to ensure optimal medication adherence. ${ }^{9}$ However, because outcomes are directly related to patients' medication-taking behavior, when clinical goals (such as serum cholesterol levels) are not being reached, adherence should be the first item assessed by the clinician.

This article provides an overview of this critical issue, focusing on the patient role in determining adherence level to lipid-lowering therapy.

\section{Adherence definition and measurement}

Several studies have measured adherence, compliance, and persistence with drug therapy; however, the terminology and methodology used for measuring these varied across studies. The general term adherence was defined by the World Health Organization in their 2001 meeting as "the extent to which a patient follows medical instructions." 10 In 2008, the Medication and Compliance Special Interest Group of the International Society for Pharmacoeconomics and Outcomes Research ${ }^{11}$ proposed two distinct concepts to be used to describe patients' medication behavior. First, the terms "compliance" and "adherence" define "the extent to which a patient acts in accordance with the prescribed interval and dose of a dosing regimen." Second, the term "persistence" defines the "the duration of time from initiation to discontinuation of therapy."

The methods available for assessing adherence can be distinguished as direct or indirect methods of measurement. ${ }^{12}$ Direct approaches, such as the measurement of concentrations of a drug or its metabolite in blood or urine, are accurate but expensive and burdensome to the health care provider. Indirect methods, including asking the patient about how easy it is for him or her to take prescribed medication or ascertaining rates of refilling prescriptions, are simple and cheap; however, patient interviews generally are considered unreliable: ${ }^{13}$ patients who report poor compliance are generally correct whereas those who deny poor adherence may not be. ${ }^{14}$ Nonetheless, questioning the patient (directly or using a questionnaire) or use of a patient diary could be good methods to investigate factors influencing how patients follow the doctor's recommendations. ${ }^{15}$

The exact rate of nonadherence is difficult to determine in studies and strongly depends on the setting, patients enrolled, data sources, and measurement methods. Nevertheless, most studies of patients prescribed statins for dyslipidemia management show variable but significantly high rates of nonadherence. Recent studies suggest that statin nonadherence is influenced by a high rate of discontinuation immediately after therapy has been initiated. ${ }^{16,17}$ Moreover, it has been demonstrated that adherence drops substantially after the first 6 months of therapy ${ }^{18,19}$ and that $25 \%-50 \%$ of new statin users discontinue the therapy during the first year. ${ }^{16,18,20,21}$ Long-term observations have shown that persistence rates decrease with time and that most statin users have at least one extended period of nonuse. ${ }^{19,20,22,23}$

\section{Adherence determinants}

Adherence is a multidimensional phenomenon ${ }^{10}$ determined by the interplay of several different factors. These can be grouped into three main categories: patient factors, physician factors, and health care system factors. ${ }^{24,25}$ Although this categorization is helpful for understanding statin adherence, there are often complex interactions between these factors that influence whether or not patients take their medications. For example, patients may fail to be adherent because of reasons as varied as attitudes toward their medications, out-of-pocket costs, side effects, the complexity of their regimens, and poor communication with their physicians. Common barriers to adherence are under the patient's control, so attention to these is a necessary and important step in improving adherence. In responses to a questionnaire, typical reasons cited by patients for not taking their medications included forgetfulness, other priorities, decision to omit doses, lack of information, and emotional factors. ${ }^{14}$ Physicians contribute to patients' poor adherence by prescribing complex regimens, failing to adequately explain the benefits and side effects of a medication, not giving consideration to the patient's lifestyle or the cost of the medications, and having poor therapeutic relationships with their patients. ${ }^{26,27}$ More broadly, health care systems create barriers to adherence by limiting access to health care, using a restricted formulary or switching to a different formulary, and having high costs for drugs, copayments, or both. ${ }^{28}$

When aggregating different determinants into patientrelated, physician-related, and system-related predictors, patient-related predictors account for the largest incremental explanatory power in predicting adherence. ${ }^{29}$ Patientrelated factors are the resources, knowledge, attitudes, beliefs, perceptions, and expectations of the patient. Patients' knowledge and beliefs about their illness, motivation to manage it, confidence in their ability to engage in illness-management behaviors, and expectations regarding the outcome of treatment and the consequences of poor adherence interact to influence adherence behavior. 
Patient-related reasons may be grouped into two simple categories: unintentional, and intentional nonadherence. ${ }^{27,30}$ Unintentional nonadherence is related to patients' skills or their ability to take their medication (eg, problems with manual dexterity or forgetfulness). Conversely, intentional nonadherence is associated with motivation and patients' beliefs about taking medications and is a conscious decision by the patient to "self-medicate" that is, decide for themselves drug, dose, and frequency of their treatment regimen.

In a study on statin-treated patients, ${ }^{31}$ the analysis of patient-survey responses showed that the most common patient-reported reasons for discontinuing statins were: adverse effects $(42.2 \%)$, felt that treatment was unnecessary (14.0\%), worry about developing adverse effects (12.7\%), physician-advised discontinuation $(8.5 \%)$, preferred to manage their condition using diet and exercise $(8.5 \%)$, felt that they were taking too many medications $(4.2 \%)$, or other $(28.2 \%)$. More discontinuers than continuers felt that the statin provided limited benefit or were unsure of the benefits of statins $(81.7 \%$ vs $46.8 \%$ ). In terms of general statin knowledge, more continuers than discontinuers knew the statin therapy would be long term $(11.3 \%$ vs $2.3 \%)$ and understood their benefits ( $72.5 \%$ vs $57.7 \%$ ). Regarding the relationships with healthcare providers, more continuers than discontinuers trusted their providers (95.3\% vs 80.3\%) and felt that they had adequate knowledge to answer their questions (94.2\% vs $75.9 \%$ ). Continuers were more likely to have had information on statins explained in ways that were easy to understand (83.7\% vs $64.8 \%)$.

\section{Lack of perception of health risk related to the disease and of need for treatment}

Perceptions of personal need for medication are influenced by symptoms, expectations and experiences, and by illness cognitions. ${ }^{32}$ According to the Health Belief Model, ${ }^{33}$ patients who have a perceived need to treat their conditions effectively are more likely to take the recommended medications.

A commonly reported barrier to adherence to medications for asymptomatic conditions is patients' lack of illness perception and of belief in medication effectiveness: as a result of the absence of symptoms linked to high cholesterol levels, hypercholesterolemic patients do not feel ill or realize that their levels should be changed. ${ }^{34}$ Avorn et $\mathrm{al}^{35}$ conducted surveys of patients deemed to have discontinued their statin and found one of the most common reasons for discontinuation to be that patients were unconvinced about the need for treatment (32\%). Most patients believed that statins effectively reduce cholesterol levels and that having a high cholesterol level is unsafe; however, many also questioned their personal need for statins. A number of participants felt that their cholesterol levels were close enough to target thresholds that statins might not be of much benefit to them. Some patients expressed a preference for controlling their cholesterol via lifestyle changes, such as exercise and diet, or alternative therapies, including herbal remedies. ${ }^{36}$

Adherence has been found to be better when the patient accepts the severity of his illness, trusts the therapist, and believes in the effectiveness of the recommended therapeutic measures. ${ }^{37,38}$ Based on this evidence, we can argue that a higher-risk condition should be characterized by higher level of adherence. Actually, Blenner et al found comorbid cardiovascular disease (CVD) (revascularization, congestive heart failure) and a history of stroke to be significant predictors of adherence. ${ }^{39}$ In an analysis of statinnaïve patients, Ellis et $\mathrm{al}^{28}$ detected a significantly higher discontinuation rate among primary-prevention patients when compared with those treated for secondary prevention, suggesting that some degree of augmented retention occurs in those most likely to benefit from statin therapy. These data are in agreement with other studies demonstrating that patients are more likely to be adherent with therapy after experiencing serious complications due to CVD, potentially due to an increased appreciation of the importance of managing their risk factors. ${ }^{35,40}$ Nevertheless, it was reported that adherence with statin therapy was less than optimal in cohorts treated for primary and secondary prevention: ${ }^{28}$ the observed level of nonadherence was undesirable and especially disappointing for individuals with documented coronary heart disease (CHD) given the greater likelihood of negative outcomes in this high-risk group. A retrospective review of over 200,000 Canadian patients ${ }^{41}$ demonstrated that $53.8 \%$ of patients had a period of nonadherence to statins lasting at least 90 days. However, there were clear events that persuaded patients to resume therapy. The most influential event was, not surprisingly, a new myocardial infarction, which resulted in an odds ratio of 12.1 of returning to therapy. More commonly, a visit with a physician made it 2.9 times more likely of a return to therapy, with a visit with the initial physician who prescribed the statin demonstrating an odds ratio likelihood of resuming therapy of 6.1, suggesting again the important role of the patient-physician relationship in adherence.

The lack of knowledge regarding why a particular treatment regimen has been prescribed and the consequences of not adhering to the intervention is compounded by the fact that physicians tend to overestimate public understanding 
of the impact of cardiovascular risk-factor management on overall health. For example, in a survey that investigated perceptions of CHD from the viewpoint of both physicians and the general public (Reassessing European Attitudes about Cardiovascular Treatment REACT study), 92\% of physicians believed that their patients were aware that cholesterol is associated with $\mathrm{CVD},{ }^{42}$ whereas only $51 \%$ of the general public knew that high cholesterol is associated with CHD. ${ }^{43}$ Moreover, only $45 \%$ of the general public surveyed were aware that CHD was the leading cause of death in their country. In USAGE, ${ }^{44}$ the largest US survey of self-reported current and former statin users, approximately one-half of all respondents reported being told either they had "high" total cholesterol or that their level was $\geq 240 \mathrm{mg} / \mathrm{dL}$ at the time of their diagnosis. Approximately $25 \%$ of study subjects had been told at their last visit that their LDL-C level put them at moderately high, high, or very high risk for CHD. Former statin users were less likely than current users to agree that their physicians had adequately explained their cholesterol levels (63\% vs 72\%) and how high cholesterol levels can affect the heart and arteries (58\% vs 69\%). Furthermore, although overall satisfaction with physician's explanation of treatment was $81 \%$ for all participants, former users were less likely than current users to be satisfied (65\% vs $83 \%)$.

\section{Why patients feel uneasy about drug therapy?}

Medication adherence has been found to be related to personal perceptions of the necessity of medication and concerns about potential adverse effects, and the way in which each individual balances the perceived benefits (necessity beliefs) against perceived risks (concerns). ${ }^{32}$ A patient's motivation to adhere to prescribed treatment is influenced by the value that he or she places on compliance to the regimen and the degree of confidence in being able to follow it. ${ }^{45}$ In addition, the concern beliefs in medications have been associated with unintentional nonadherence, as resulted from forgetfulness and carelessness in taking medications. ${ }^{46,47}$ Concerns about medication typically arise from beliefs about side effects and disruption of lifestyle, and from more abstract worries about long-term effects and dependence. They are related to negative views about medicines as a whole. ${ }^{48}$ One study suggests that many people have a fairly negative view of medicines, perceiving these to be generally harmful substances that are overused by doctors. ${ }^{49}$ Khanderia et a ${ }^{50}$ queried a postcoronary artery bypass graft population about their perceived utility of secondary-prevention medications after surgery. Using a validated "Beliefs about Medicine" questionnaire, they found that nonadherent patients were more likely to be in agreement with "general overuse" and "harm from cardiovascular medications."

In a patient survey by Horne and Weinman, ${ }^{32}$ although the majority of patients believed that their prescribed medication was necessary for maintaining health, approximately one-third had strong concerns about the potential adverse effects of taking it, and stronger concerns were associated with lower reported adherence. A survey study reported in $2007^{31}$ suggested that patients who were concerned about the adverse effects of statins or uncertain about the potential benefits were more likely to discontinue statin use. In a focus-group study by Fung et al, ${ }^{36}$ many participants expressed concerns about potential long-term effects of statins, including specifically, liver and kidney damage, and depletion of coenzyme Q10. In each of the focus groups, the participants talked extensively about the potential adverse effects of statins, and for many, these concerns were the primary reason they stopped taking statins. In an interesting analysis by Reaume et al, ${ }^{51}$ the effect of public perception of medication safety on statin adherence was explored. They studied the period of time immediately following the withdrawal of cerivastatin from the market for safety concerns and found that, among postacute coronary syndrome patients, there were temporary declines in use of all statins during the period, but not in use of beta-blockers or angiotensin-converting-enzyme inhibitors (ACE-inhibitors), suggesting that the concerns were medication class specific and potentially affected by the publicity surrounding cerivastatin.

\section{Complexity of the drug regimen}

Statins are one of the most effective treatments in medicine. However, several controversies remain about which patients should be treated and at what doses. The most widely recommended approach to statin therapy is an LDL-C-based, "treat to target" strategy, in which lipid-modifying therapy starts at low dose and then is titrated to achieve specific LDL-C levels..$^{52}$ Many have questioned the merits of treat-to-target approaches, highlighting a potential limitation: doubling the statin dose can increase the risk of myalgia and/or elevations in liver or muscle enzymes, with potential problems of safety and tolerability. 53,54 The alternative to the traditional "start low and titrate" strategy ${ }^{55,56}$ is to choose the initial statin dose according to a patient's baseline LDL-C level, global $\mathrm{CHD}$ risk profile, and percent reduction needed to attain his or her treatment goal. This strategy reduces the number of follow-up visits and repeat laboratory tests necessary in the 
titration process, increases compliance and convenience for the patient, and minimizes management costs.

Because many patients have multiple chronic conditions, therapeutic regimens often involve multiple medications and frequent daily dosing. Such regimen complexity may undermine effective chronic disease management. Actually, polypharmacy is common in patients at risk of CVD due to the multifactorial etiology of the disease. Furthermore, patients may have one or more comorbidities that necessitate the use of additional noncardiovascular medications. A study of a large cohort of individuals filling prescriptions for statins or antihypertensive drugs demonstrated the enormous complexity faced by patients with cardiovascular disease. ${ }^{57}$ During a 3-month period, patients filled prescriptions for a mean of 11.4 medications, representing a mean of 5.9 different drug classes. More striking, during this same time frame, $10 \%$ of patients filled prescriptions for 23 or more medications, twelve or more unique medications, and eleven or more different drug classes, had prescriptions written by four or more prescribers, filled them at two or more pharmacies, and made eleven or more visits to the pharmacy.

It has been suggested that polypharmacy may have an adverse effect on adherence because patients may not understand their complex dosing regimens and/or experience problems in organizing their daily schedules to accommodate these regimens. ${ }^{58}$ In a telephone survey by Gialamas et al, ${ }^{59}$ all patients believed that they needed to take their cholesterol medication regularly but over half of all patients reported forgetting to take their medication, and about one-quarter intentionally missed out a dose on occasion or stopped taking it for a while. In another study, around one-third of patients receiving both antihypertensive and lipid-lowering therapies were adherent to their medication after six months, although adherence was improved if both drugs were initiated at the same time. ${ }^{60}$

Chapman et $\mathrm{al}^{60}$ found lower rates of adherence to lipid-lowering and antihypertensive therapy for patients consuming greater numbers of other medications, a result that is consistent with the improvements in adherence that result from switching patients to combination pills ${ }^{61}$ and which may reflect true difficulties that patients face in following complex treatment regimens. Benner et $\mathrm{al}^{39}$ measured the association between incremental prescription burden and medication adherence and found that the former was a significant predictor of nonadherence, as patients taking the fewest medications during the preceding year had the highest likelihood of adherence to their regimen.
They observed that this association was not linear, but followed a continuous curve, with the greatest drop in adherence apparent between patients taking zero and one prior medication(s). These findings may help to explain evidence that reducing the number of medications with fixed-dose combination products is associated with higher adherence and patient satisfaction. ${ }^{39}$

On the contrary, other previous studies of prescription insurance claims found that patients who claimed a greater number of concurrent medications were more adherent to their statins. ${ }^{62}$ Authors have suggested that patients prescribed multiple concurrent medicines likely feel more personally vulnerable to the consequences of disease and therefore may be more adherent to prescribed medicines compared with healthier patients. One explanation for the contrasting findings may be that statin adherence improves with increasing medication burden up to a certain threshold, beyond which it declines. Patients prescribed the highest number of total medicines may be significantly sicker, and for these patients, the burden of illness itself may reduce medication adherence. In fact, in another study, patients treated with statins who were taking four to six other medications were more than twice as likely to report high adherence as those taking fewer than four or more than six other medications. ${ }^{63}$

In a recent systematic review and meta-analysis aimed to identify reliable predictors of nonadherence to statins, ${ }^{64}$ regimen complexity was found in eight studies to be possible predictor of adherence to statins. Overall, authors found no clear pattern of association between the total number of medications people were prescribed and their adherence to statins. There was a relatively strong relationship between increasing number of noncardiovascular medications and low statin adherence. In contrast, an increasing number of cardiovascular medications was associated with higher statin adherence.

In addition to polypharmacy, other factors may add complexity to a patient's medication regimen and adversely affect adherence. Patients interact with physicians to have medications prescribed and visit pharmacies to fill their prescriptions. As a result, among patients prescribed equivalent numbers of medications and with equal levels of illness severity, those patients who make numerous trips to the pharmacy to pick up their medications, those for whom multiple physicians write prescriptions, and those patients who fill prescriptions at many different pharmacies, may have greater difficulty taking their medications as prescribed. The cohort study by Choudhry et $\mathrm{al}^{57}$ showed that, controlling for the number of medications used, patients who made visits 
to more pharmacies and those who filled fewer medications per visit were substantially less adherent to their prescribed therapy. The magnitude of these effects was particularly large for patients who had newly initiated therapy.

\section{Lack of efficacy}

In many countries, initial lipid-lowering treatment is dominated by statin monotherapy at low- to mid-equipotency doses and infrequently includes adjunctive therapies. These statin doses often are not consistent with the patient's baseline absolute cardiovascular risk and LDL-C targets. The use of inadequate doses is generally recognized as one of the reasons for the low success rate in achieving LDL-C targets. ${ }^{65}$ Moreover, most patients who begin treatment with statins remain on initial doses despite failure to achieve their target, a phenomenon known as 'clinical inertia'. ${ }^{66}$ In the LIPI-WATCH survey, $77 \%$ of patients were maintained on the starting dose even though they had not reached the target. ${ }^{67}$ Few patients were treated with dosages tested in randomized clinical trials or dosages required to achieve treatment goals. ${ }^{68}$ Similarly, in another study, $88 \%$ of patients who did not achieve their LDL-C goal were maintained on the same dose of statin for at least 1 year, and only $3 \%$ were receiving the maximal dose. ${ }^{69}$

Recognizing that long-term adherence to lipid-lowering treatment is a challenge, guidelines ${ }^{52,70}$ recommend that patients return for reevaluation 6 to 8 weeks after treatment initiation and dosage adjustment, and every 4 to 6 months once treatment goals have been achieved. The primary objectives of close follow up are to monitor the effectiveness of drug therapy and to promote patient compliance. Benner et $\mathrm{al}^{71}$ hypothesized that achieving favorable results during the first few weeks of therapy may be an important component of self-efficacy and may therefore promote longterm adherence. To test this hypothesis, they conducted a 3 -year, retrospective, cohort study of statin use in a group of new statin users, observing that patients who had the smallest change in LDL-C had the lowest rates of adherence over time. Another analysis, by Benner et al, ${ }^{40}$ found that although history of stroke, chronic heart failure, diabetes, or hypertension predicted better persistence, patients who had a myocardial infarction after starting statin therapy were significantly less likely to continue their statin use following the event, perhaps because they perceived the drug to be ineffective.

\section{Adverse effects}

The side effects of statins experienced by patients are also an important cause of nonadherence to medication. A recent analysis of statin adverse drug reactions (ADR) in the (Food and Drug Administration) FDA's adverse event reporting system, AERS, found signals for myalgia, rhabdomyolysis, and an increase in creatine phosphokinase level and other common muscular ADR, including asthenia, chest pain, pain in the extremities, muscle spasms, muscular weakness, myositis, and myopathy. ${ }^{72}$ Muscular symptoms associated with average dosage statin therapy are more frequent than in clinical trials and have a greater impact on patients' life than usually thought. ${ }^{73,74}$ In a recently published review, it was suggested that the muscular symptoms occurred in up to $20 \%$ of patients in observational studies. ${ }^{75}$ Moreover, statin-related muscular side effects were more present in older people. ${ }^{73,76}$ It can be postulated that older patients more likely have other conditions that can interfere with statin metabolism (such as renal insufficiency) or mimic statin muscular side effects and that statin pharmacokinetics is different in this population.

In an observational study of patients with dyslipidemia receiving high doses of statins, ${ }^{74}$ these symptoms were reported by $10.5 \%$ of patients, of which $19.8 \%$ discontinued their statin therapy and $16.7 \%$ required a dose reduction. Most of the muscle side effects occurred within the first 3 months. In a wide survey on French subjects, muscular symptoms were reported by $10 \%$ of statin-treated patients and led to discontinuation in $30 \%$ of the symptomatic patients. ${ }^{73}$ In a survey by Cohen et al, ${ }^{44}$ muscle-related side effects while taking a statin were reported by $29 \%$ of all survey participants: $25 \%$ among current users and 60\% among former users. Of former statin users, $62 \%$ indicated side effects as the reason for stopping, compared with $17 \%$ who indicated costs and 12\% who cited lack of efficacy. Former users also described themselves as less likely to tolerate side effects from prescription medications. Most respondents discussed these side effects with their doctor, and it was the physician who most frequently recommended stopping or switching statins as the course of action. However, approximately one-third of those who stopped their statin because of muscle-related side effects did so without talking to their doctor.

In the communication between patients and physicians about ADRs, the latter play an important role. Using a patient-targeted survey, the authors of one study sought to assess patient representations of how physicians responded when patients presented with possible ADRs. ${ }^{77}$ In this study, $87 \%$ of patients spoke to their physician about the possible connection between statin use and their symptom. Physicians were commonly reported to have denied the possibility of a relationship between symptoms and drug, and to have done 
so even when the patient noticed and reported an apparent association, when there was literature support for the ADR, and when cases met literature criteria for probable or definite ADR causality. According to patients, physicians seldom initiated the conversations regarding a possible relation of the drug to the symptom.

\section{Costs}

The cost of medications remains a controversial cause of nonadherence. The largest analysis evaluating the cost of medicines and adherence found that in 132 studies, an increase in cost sharing was associated with lower rates of drug treatment, worse adherence, and more frequent discontinuation of therapy. ${ }^{78}$ The authors found that medication use fell by $2 \%-6 \%$ for a $10 \%$ increase in cost sharing. Similarly, the analysis by Ellis et $\mathrm{al}^{28}$ highlighted that the level of patient copayment was an independent factor for statin discontinuation.

A Finnish study ${ }^{79}$ evaluated the difference between adherence to medications on the basis of cost by comparing the discontinuation rates of atorvastatin with the recently introduced, generic simvastatin in 2003. In the initial year following generic statin availability, there were no differences in discontinuation rates; however, 2 years later, those who started simvastatin were $20 \%$ less likely to discontinue statin therapy. Interestingly, when patients' copayments were reimbursed, this difference in discontinuation rates again disappeared, confirming that cost does play a role in medication adherence.

\section{The patient-physician relationship}

Adherence has been defined as "the active, voluntary, and collaborative involvement of the patient in a mutually acceptable course of behavior to produce a therapeutic result." 80 Osterberg and Blaschke ${ }^{25}$ reported that the word "adherence" is preferred by many health care providers, because "compliance" suggests that the patient is passively following the doctor's orders and that the treatment plan is not based on a therapeutic alliance or contract established between the patient and the physician.

Although most patients could identify what causes hyperlipidemia, the majority of patients did not understand how their cholesterol-lowering medication worked. It is possible that these gaps in understanding are more attributable to a lack of provision of appropriate education than to the patients' ability to comprehend. Two major problems in the doctor-patient relationship are the patient's dissatisfaction with the communication aspect of the consultation and the patients not following advice given to them. ${ }^{6,81}$ Studies have shown that the quality of clinical communication is related to positive health outcomes. ${ }^{81,82}$ Concordance between the doctor and patient in identifying the nature and seriousness of the clinical problem is related to improving and resolving the problem, and greater participation by the patient in the encounter improves satisfaction, compliance and outcome of treatment. An improvement in clinical communication can be obtained, encouraging patients to discuss their main concerns without interruption or premature closing. Patients' perceptions of the illness and associated feelings and expectations should be elicited, and doctors should cultivate empathy, learn methods of active listening, give clear explanations, check the patient's understanding, negotiate a treatment plan, and check the patient's attention to compliance. ${ }^{6}$ Gaining a better understanding of the range of underlying motivations for discontinuing therapy is critical for designing effective interventions. Identifying the types and sources of information patients use to learn about statins and their perceptions of cardiovascular risk factors could also improve clinician-patient communication about statins. Stressing the benefits of statin therapy at the time of prescribing, as well as discussing potential adverse side effects and their incidence and seriousness, may improve how patients filter information they receive from other sources. The patient's perception of the time that his physician spent to explain and to discuss the different aspects of cholesterol and the CVD problem has been directly correlated with a higher compliance. ${ }^{83}$

\section{Conclusion}

There are a number of direct patient-related reasons for nonadherence to antihypertensive and lipid-lowering medicines. These include forgetfulness, a negative attitude towards medication, frustration with poor therapeutic responses, and preconceived beliefs regarding health and medication. In addition, a poor understanding of the cost-benefit analysis of a prescribed drug, including a lack of understanding of the benefit of the medication and a fear of drug-related adverse events, may also contribute to patient nonadherence.

Building on the patient's motivation, by increasing the perceived importance of adherence, and strengthening confidence, by building self-management skills, are behavioral treatment targets that must be addressed concurrently with biomedical ones if overall adherence is to be improved.

\section{Disclosure}

The authors have no conflicts of interest to disclose. 


\section{References}

1. World Health Organization. Global Status Report on Noncommunicable Diseases. Geneva: World Health Organization; 2010. Available from: http://www.who.int/nmh/publications/ncd_report2010/en/. Accessed October 15, 2012.

2. Centers for Disease Control and Prevention (CDC). Vital signs: prevalence, treatment, and control of high levels of low-density lipoprotein cholesterol - United States, 1999-2002 and 2005-2008. MMWR Morb Mortal Wkly Rep. 2011;60(4):109-114.

3. Kotseva K, Wood D, De Backer G, De Bacquer D, Pyörälä K, Keil U; for EUROASPIRE Study Group. Cardiovascular prevention guidelines in daily practice: a comparison of EUROASPIRE I, II, and III surveys in eight European countries. Lancet. 2009;373(9667):929-940.

4. Straka RJ, Taheri R, Cooper SL, Tan AW, Smith AC. Assessment of hypercholesterolemia control in a managed care organization. Pharmacotherapy. 2001;21(7):818-827.

5. Davidson MH. Differences between clinical trial efficacy and real-world effectiveness. Am J Manag Care. 2006;12(Suppl 15):S405-S411.

6. Vermeire E, Hearnshaw H, Van Royen P, Denekens J. Patient adherence to treatment: three decades of research. A comprehensive review. J Clin Pharm Ther. 2001;26(5):331-342.

7. Bates TR, Connaughton VM, Watts GF. Non-adherence to statin therapy: a major challenge for preventive cardiology. Expert Opin Pharmacother. 2009;10(18):2973-2985.

8. Helin-Salmivaara A, Lavikainen PT, Korhonen MJ, et al. Pattern of statin use among 10 cohorts of new users from 1995 to 2004: a register-based nationwide study. Am J Manag Care. 2010;16(2):116-122.

9. Schedlbauer A, Davies P, Fahey T. Interventions to improve adherence to lipid lowering medication. Cochrane Database Syst Rev. 2010; 17(3):CD004371.

10. Sabaté E; World Health Organization, Noncommunicable Diseases and Mental Health Cluster. Adherence to Long-term Therapies: Policy for Action: Meeting Report, 4-5 June 2001. Geneva: World Health Organization; 2001. Available from: http://apps.who.int/iris/ handle/10665/66984. Accessed October 15, 2012.

11. Cramer JA, Roy A, Burrell A, et al. Medication compliance and persistence: terminology and definitions. Value Health. 2008;11(1):44- 47.

12. Farmer KC. Methods for measuring and monitoring medication regimen adherence in clinical trials and clinical practice. Clin Ther. 1999;21(6): 1074-1090; discussion 1073.

13. Garber MC, Nau DP, Erickson SR, Aikens JE, Lawrence JB. The concordance of self-report with other measures of medication adherence: a summary of the literature. Med Care. 2004;42(7):649-652.

14. Cramer JA, Spilker B, editors. Patient Compliance in Medical Practice and Clinical Trials. New York: Raven Press; 1991.

15. Garfield S, Clifford S, Eliasson L, Barber N, Wilson A. Suitability of measures of self-reported medication adherence for routine clinical use: A systematic review. BMC Med Res Methodol. 2011; 11:149.

16. Corrao G, Conti V, Merlino L, Catapano AL, Mancia G. Results of a retrospective database analysis of adherence to statin therapy and risk of nonfatal ischemic heart disease in daily clinical practice in Italy. Clin Ther. 2010;32(2):300-310.

17. Lemstra M, Blackburn D. Nonadherence to statin therapy: discontinuation after a single fill. Can J Cardiol. 2012;28(5):567-573.

18. Perreault S, Blais L, Dragomir A, et al. Persistence and determinants of statin therapy among middle-aged patients free of cardiovascular disease. Eur J Clin Pharmacol. 2005;61(9):667-674.

19. Simons LA, Ortiz M, Calcino G. Long term persistence with statin therapy-experience in Australia 2006-2010. Aust Fam Physician. 2011; 40(5):319-322.

20. Helin-Salmivaara A, Lavikainen P, Korhonen MJ, et al. Long-term persistence with statin therapy: a nationwide register study in Finland. Clin Ther. 2008;30 Pt 2:2228-2240.

21. Mantel-Teeuwisse AK, Goettsch WG, Klungel OH, de Boer A, Herings RM. Long term persistence with statin treatment in daily medical practice. Heart. 2004;90(9):1065-1066.
22. Korhonen MJ, Helin-Salmivaara A, Huupponen R. Dynamics of longterm statin therapy. Eur J Clin Pharmacol. 2011;67(9):925-931.

23. Vinker S, Shani M, Baevsky T, Elhayany A. Adherence with statins over 8 years in a usual care setting. Am J Manag Care. 2008;14(6):388-392.

24. Mauskop A, Borden WB. Predictors of statin adherence. Curr Cardiol Rep. 2011;13(6):553-558.

25. Osterberg L, Blaschke T. Adherence to medication. $N$ Engl J Med. 2005;353(5):487-497.

26. Mechanic D, editor. The Growth of Bureaucratic Medicine: An Inquiry into the Dynamics of Patient Behavior and the Organization of Medical Care. New York: Wiley; 1976.

27. Meichenbaum D, Turk DC. Facilitating Treatment Adherence: A Practitioner's Guidebook. New York: Plenum Press; 1987.

28. Ellis JJ, Erickson SR, Stevenson JG, Bernstein SJ, Stiles RA, Fendrick AM. Suboptimal statin adherence and discontinuation in primary and secondary prevention populations. J Gen Intern Med. 2004;19(6):638-645.

29. Chan DC, Shrank WH, Cutler D, et al. Patient, physician, and payment predictors of statin adherence. Med Care. 2010;48(3):196-202.

30. Haynes RB, Sackett DL, editors. Compliance with Therapeutic Regimens. Baltimore: Johns Hopkins University Press; 1976.

31. McGinnis B, Olson KL, Magid D, et al. Factors related to adherence to statin therapy. Ann Pharmacother. 2007;41(11):1805-1811.

32. Horne R, Weinman J. Patients' beliefs about prescribed medicines and their role in adherence to treatment in chronic physical illness. J Psychosom Res. 1999;47(6):555-567.

33. Janz NK, Becker MH. The Health Belief Model: a decade later. Health Educ Q. 1984;11(1):1-47.

34. Durack-Bown I, Giral P, d'Ivernois JF, et al. Patients' and physicians' perceptions and experience of hypercholesterolaemia: a qualitative study. Br J Gen Pract. 2003;53(496):851-857.

35. Avorn J, Monette J, Lacour A, et al. Persistence of use of lipidlowering medications: a cross-national study. JAMA. 1998;279(18): 1458-1462.

36. Fung V, Sinclair F, Wang H, Dailey D, Hsu J, Shaber R. Patients' perspectives on nonadherence to statin therapy: a focus-group study. Perm J. 2010;14(1):4-10.

37. Ho KT, Chin KW, Ng KS, Alemao E, Rajagopalan S, Yin D. The A-SACT (Achievement in Singapore of Cholesterol Targets) study in patients with coronary heart disease. Am J Cardiovasc Drugs. 2006;6(6): 383-391.

38. Bardel A, Wallander MA, Svärdsudd K. Factors associated with adherence to drug therapy: a population-based study. Eur J Clin Pharmacol. 2007;63(3):307-314.

39. Benner JS, Chapman RH, Petrilla AA, Tang SS, Rosenberg N, Schwartz JS. Association between prescription burden and medication adherence in patients initiating antihypertensive and lipid-lowering therapy. Am J Health Syst Pharm. 2009;66(16):1471-1477.

40. Benner JS, Glynn RJ, Mogun H, Neumann PJ, Weinstein MC, Avorn J. Long-term persistence in use of statin therapy in elderly patients. JAMA. 2002;288(4):455-461.

41. Brookhart MA, Patrick AR, Schneeweiss S, et al. Physician follow-up and provider continuity are associated with long-term medication adherence: a study of the dynamics of statin use. Arch Intern Med. 2007;167(8):847-852.

42. Hobbs FD, Erhardt L. Acceptance of guideline recommendations and perceived implementation of coronary heart disease prevention among primary care physicians in five European countries: the Reassessing European Attitudes about Cardiovascular Treatment (REACT) survey. Fam Pract. 2002;19(6):596-604.

43. Erhardt L, Hobbs FD. Public perceptions of cardiovascular risk in five European countries: the react survey. Int J Clin Pract. 2002; 56(9):638-644.

44. Cohen JD, Brinton EA, Ito MK, Jacobson TA. Understanding Statin Use in America and Gaps in Patient Education (USAGE): an internetbased survey of 10,138 current and former statin users. J Clin Lipidol. 2012;6(3):208-215. 
45. Miller WR, Rollnick S. Motivational Interviewing: Preparing People to Change Addictive Behavior. New York: Guilford Press; 1991.

46. Gadkari AS, McHorney CA. Unintentional non-adherence to chronic prescription medications: how unintentional is it really? BMC Health Serv Res. 2012;12:98.

47. Unni EJ, Farris KB. Unintentional non-adherence and belief in medicines in older adults. Patient Educ Couns. 2011;83(2):265-268.

48. Horne R, Hankins M, Jenkins R. The Satisfaction with Information about Medicines Scale (SIMS): a new measurement tool for audit and research. Qual Health Care. 2001;10(3):135-140.

49. Horne R, Weinman J, Hankins M. The beliefs about medicines questionnaire: The development and evaluation of a new method for assessing the cognitive representation of medication. Psychology and Health. 1999;14(1):1-24.

50. Khanderia U, Townsend KA, Erickson SR, Vlasnik J, Prager RL, Eagle KA. Medication adherence following coronary artery bypass graft surgery: assessment of beliefs and attitudes. Ann Pharmacother. 2008;42(2):192-199.

51. Reaume KT, Erickson SR, Dorsch MP, et al. Effects of cerivastatin withdrawal on statin persistence. Ann Pharmacother. 2008;42(7): 956-961.

52. National Cholesterol Education Program (NCEP) Expert Panel on Detection, Evaluation, and Treatment of High Blood Cholesterol in Adults (Adult Treatment Panel III). Third Report of the National Cholesterol Education Program (NCEP) Expert Panel on Detection, Evaluation, and Treatment of High Blood Cholesterol in Adults (Adult Treatment Panel III) final report. Circulation. 2002;106(25): 3143-3421.

53. Maron DJ, Fazio S, Linton MF. Current perspectives on statins. Circulation. 2000;101(2):207-213.

54. Roberts WC. The rule of 5 and the rule of 7 in lipid-lowering by statin drugs. Am J Cardiol. 1997;80(1):106-107.

55. Grundy SM, Cleeman JI, Merz CN, et al; for National Heart, Lung, and Blood Institute; American College of Cardiology Foundation; American Heart Association. Implications of recent clinical trials for the National Cholesterol Education Program Adult Treatment Panel III guidelines. Circulation. 2004;110(2):227-239.

56. Catapano AL. Perspectives on low-density lipoprotein cholesterol goal achievement. Curr Med Res Opin. 2009;25(2):431-447.

57. Choudhry NK, Fischer MA, Avorn J, et al. The implications of therapeutic complexity on adherence to cardiovascular medications. Arch Intern Med. 2011;171(9):814-822.

58. Munger MA, Van Tassell BW, LaFleur J. Medication nonadherence: an unrecognized cardiovascular risk factor. Med Gen Med. 2007; 9(3):58.

59. Gialamas A, Aylward P, Vanlint S, Stocks NP. Cholesterol lowering medication - patients' knowledge, attitudes and experiences. Aust Fam Physician. 2011;40(7):519-522.

60. Chapman RH, Petrilla AA, Benner JS, Schwartz JS, Tang SS. Predictors of adherence to concomitant antihypertensive and lipid-lowering medications in older adults: a retrospective, cohort study. Drugs Aging. 2008;25(10):885-892.

61. Bangalore S, Kamalakkannan G, Parkar S, Messerli FH. Fixed-dose combinations improve medication compliance: a meta-analysis. Am J Med. 2007;120(8):713-719.

62. Grant RW, O'Leary KM, Weilburg JB, Singer DE, Meigs JB. Impact of concurrent medication use on statin adherence and refill persistence. Arch Intern Med. 2004;164(21):2343-2348.

63. Natarajan N, Putnam RW, Yip AM, Frail D. Family practice patients' adherence to statin medications. Can Fam Physician. 2007;53(12): 2144-2145.

64. Mann DM, Woodward M, Muntner P, Falzon L, Kronish I. Predictors of nonadherence to statins: a systematic review and meta-analysis. Ann Pharmacother. 2010;44(9):1410-1421.
65. Pearson TA, Laurora I, Chu H, Kafonek S. The lipid treatment assessment project (L-TAP): a multicenter survey to evaluate the percentages of dyslipidemic patients receiving lipid-lowering therapy and achieving low-density lipoprotein cholesterol goals. Arch Intern Med. 2000;160(4):459-467.

66. Phillips LS, Branch WT, Cook CB, et al. Clinical inertia. Ann Intern Med. 2001;135(9):825-834.

67. Muls E, De Bbacker G, De Bacquer D, Brohet M, Heller F; for LIPIWATCH Investigators. LIPI-WATCH, a Belgian/Luxembourg survey on achievement of European Atherosclerosis Society lipid goals. Clin Drug Invest. 2000;19(3):219-229.

68. Lablanche JM. Achieving LDL-C target levels: the role of statins. Curr Med Res Opin. 2001;16(4):285-295.

69. Marcelino JJ, Feingold KR. Inadequate treatment with HMG-CoA reductase inhibitors by health care providers. Am J Med. 1996;100(6): 605-610.

70. Catapano AL, Reiner Z, De Backer G, et al; for European Society of Cardiology (ESC); European Atherosclerosis Society (EAS). ESC/ EAS Guidelines for the management of dyslipidaemias: the Task Force for the management of dyslipidaemias of the European Society of Cardiology (ESC) and the European Atherosclerosis Society (EAS). Atherosclerosis. 2011;217(1):3-46.

71. Benner JS, Pollack MF, Smith TW, Bullano MF, Willey VJ, Williams SA. Association between short-term effectiveness of statins and long-term adherence to lipid-lowering therapy. Am J Health Syst Pharm. 2005;62(14):1468-1475.

72. Sakaeda T, Kadoyama K, Okuno Y. Statin-associated muscular and renal adverse events: data mining of the public version of the FDA adverse event reporting system. PLoS One. 2011;6(12):e28124.

73. Rosenbaum D, Dallongeville J, Sabouret P, Bruckert E. Discontinuation of statin therapy due to muscular side effects: A survey in real life. Nutr Metab Cardiovasc Dis. Epub June 28, 2012.

74. Bruckert E, Hayem G, Dejager S, Yau C, Bégaud B. Mild to moderate muscular symptoms with high-dosage statin therapy in hyperlipidemic patients-the PRIMO study. Cardiovasc Drugs Ther. 2005;19(6): 403-414.

75. Fernandez G, Spatz ES, Jablecki C, Phillips PS. Statin myopathy: a common dilemma not reflected in clinical trials. Cleve Clin J Med. 2011;78(6):393-403.

76. Abd TT, Jacobson TA. Statin-induced myopathy: a review and update. Expert Opin Drug Saf. 2011;10(3):373-387.

77. Golomb BA, McGraw JJ, Evans MA, Dimsdale JE. Physician response to patient reports of adverse drug effects: implications for patient-targeted adverse effect surveillance. Drug Saf. 2007;30(8):669-675.

78. Goldman DP, Joyce GF, Zheng Y. Prescription drug cost sharing: associations with medication and medical utilization and spending and health. JAMA. 2007;298(1):61-69.

79. Helin-Salmivaara A, Korhonen MJ, Alanen T, Huupponen R. Impact of out-of-pocket expenses on discontinuation of statin therapy: a cohort study in Finland. J Clin Pharm Ther. 2012;37(1):58-64.

80. Ho PM, Bryson CL, Rumsfeld JS. Medication adherence: its importance in cardiovascular outcomes. Circulation. 2009;119(23): 3028-3035.

81. Simpson M, Buckman R, Stewart M, et al. Doctor-patient communication: the Toronto consensus statement. BMJ. 1991;303(6814):1385-1387.

82. Stewart MA. Effective physician-patient communication and health outcomes: a review. CMAJ. 1995;152(9):1423-1433.

83. Kiortsis DN, Giral P, Bruckert E, Turpin G. Factors associated with low compliance with lipid-lowering drugs in hyperlipidemic patients. J Clin Pharm Ther. 2000;25(6):445-451. 
Patient Preference and Adherence

Dovepress

\section{Publish your work in this journal}

Patient Preference and Adherence is an international, peer-reviewed, open access journal focusing on the growing importance of patient preference and adherence throughout the therapeutic continuum. Patient satisfaction, acceptability, quality of life, compliance, persistence and their role in developing new therapeutic modalities and compounds to

optimize clinical outcomes for existing disease states are major areas of interest. This journal has been accepted for indexing on PubMed Central. The manuscript management system is completely online and includes a very quick and fair peer-review system. Visit http://www.dovepress.com/ testimonials.php to read real quotes from published authors.

Submit your manuscript here: http://www.dovepress.com/patient-preference-and-adherence-journal 